\title{
Facing the Future: the Changing Shape of Academic Skills Support at Bournemouth University
}

\author{
Neil Ford \\ Bournemouth University, UK \\ Melissa Bowden \\ Bournemouth University, UK
}

\begin{abstract}
This paper explores the potential impact of changes to higher education in England on student expectations, engagement, lifestyles and diversity, and outlines implications for the development of digital literacy within academic skills support at Bournemouth University (BU). We will investigate how tackling resource constraints with organisational change can also enable efficient, centralised provision of support materials that utilise networks to overcome the risk of fragmented support for digital literacy. We will also look at how changing delivery modes for support can accommodate changing student lifestyles whilst tackling a weakness of centralised support for digital literacy: that it can become detached from the student's subject-focused academic practice. Finally we will explore how involving students in developing support can help us to face changes to student expectations and engagement whilst ensuring that materials are authentic and speak to learners in their own voice.
\end{abstract}

Keywords: digital literacy; social media; organisational change; higher education; learning support; academic skills.

\section{Organisational change for efficiency and silo busting!}

'The Browne Report' (Independent Review of Higher Education and Student Finance in England, 2010) and 'Higher Education: Students at the Heart of the System' (Department for Business Innovation and Skills, 2011) both herald an age where learners will pay more 
directly for their education than ever before. There are no certainties about how this will affect change, but it is safe to assume that organisational change will be a feature in how universities cope with financial uncertainty. We should see these changes as opportunities to look at how our organisational structures support digital literacy.

The organisational position of learning support varies greatly across the sector and has been subject to a great deal of change over the past twenty years. Some institutions locate support within academic departments, whilst for others it sits within centralised, professional services. In some cases, support comes from a combination of professional and academic departments (Hanson, 2005). Perhaps particularly relevant to support for digital literacy is the concept of 'convergence' - the bringing together of services such as IT and computing, libraries and information resources, and learning support (Biddiscombe, 1999). This has led to a blurring of roles, for example with librarians increasingly taking on support for IT and pedagogic support (Biddiscombe, 2002). This is coincident with the emergence of learning technology as a discipline, and again there is great variation in roles supporting blended and e-learning and where these roles sit within the organisation (Ooms et al., 2008).

Goodfellow (2011) provides interesting commentary on the evolution of the plural term 'digital literacies' as incorporating a range of other literacies 'including information and communications technology (ICT) literacy, technology literacy, information literacy, media literacy, visual literacy and communications literacy' (Goodfellow, 2011, p.133). It is not uncommon for these skills and practices to be supported by separate departments within universities (Beetham et al., 2010). To a student, such centralised support can become compartmentalised: requiring them to contact various different departments, different communities of practice with different approaches to skills development (Goodfellow, 2011).

An example of this used to be found in the online skills support communities within the virtual learning environment (VLE) at BU. Previously, there was an Information Skills Community managed by the library and an Academic Skills Community managed by learning support. This was an artificial division based on our organisational structure rather than the way students wanted to access support. Why should they go to one place for guidance on essay writing, but another for help with referencing? In 2010, this division was remedied by integrating support materials into a single, new Academic Skills Community 
on the VLE. This was made possible by organisational change, which brought together librarians, learning technologists and languages support into a single section called Library and Learning Support (LLS) with a remit for academic skills. The new community benefitted from the professional skills of librarians in selecting and organising the materials and the technical skills of learning technologists in designing the interface and integrating the community within the VLE. It also benefitted from the educational experience of the extended group, which includes practitioners with teaching qualifications, fellows of the HEA, postgraduate researchers, and an expert on languages and academic writing.

Support for referencing and plagiarism at BU provides another example of how organisational change has helped to avoid a 'systemic' problem of centralised support: that individual competencies can become divorced from each other in the overall development of academic practice (Beetham et al., 2010, p.4). Whilst introducing online assignment handling, we have seen cross-over between the academic practice of avoiding plagiarism, which has traditionally been supported by librarians in partnership with academics, and the digital practice of producing and submitting a piece of work for use with plagiarism and submission software, supported by learning technologists. By working as a team, we have been able to integrate support for these practices.

Before submitting assignments, BU students are now encouraged to produce a formative plagiarism report using our anti-plagiarism software (Turnitin). Subject librarians have embedded instructions on how to use the software (based on guidance from learning technologists) into referencing sessions with students. They have also made changes to referencing support (Student and Academic Services, 2010) to encourage students to reference in a way that enables the plagiarism software to detect legitimate quotes, rather than misinterpret them as plagiarism. On the other hand, learning technologists have closely embedded support from subject librarians into online submission guidance, which directs any students who are concerned about their plagiarism report to contact their subject librarian for help. 


\section{Figure 1. Library and Learning Support structure.}

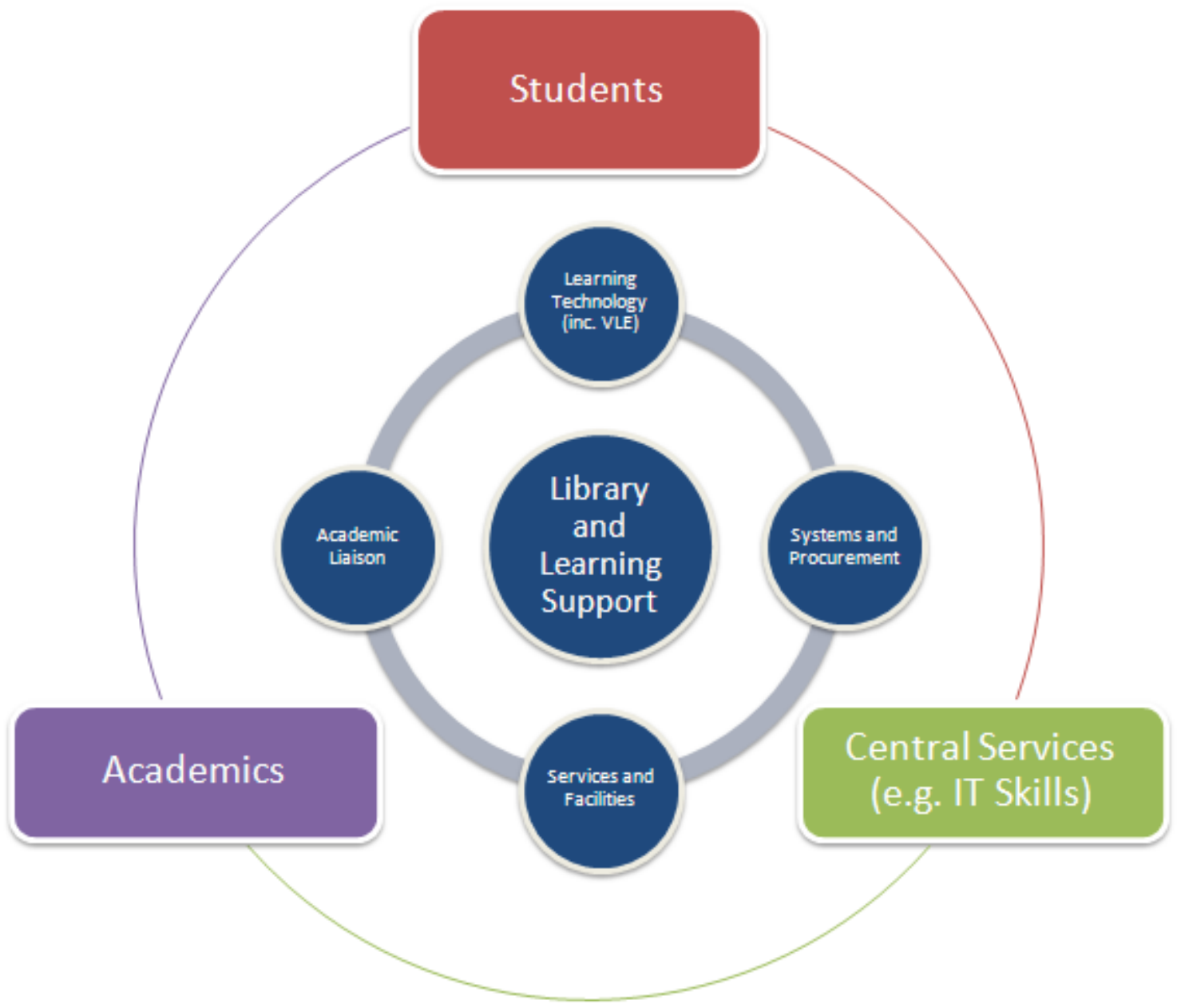

Organisationally, Library and Learning Support are well placed to promote the embedding of digital literacy support into curricula. Librarians and learning technologists work closely with academic departments, which can offer us opportunities to deeply embed our support for skills development into unit learning outcomes, activities and assessment through involvement in curriculum development. For example, all of our Subject Librarians and Academic Support Librarians deliver support for 'skills' units on the programmes that they work with. Moving forwards our aim is to increase this distributed support whilst our Academic Skills Community provides access to both online and face-to-face support for students who choose to develop their skills independently. We are also well placed to integrate support for digital literacy with personal growth and professional development opportunities being coordinated by other central departments in response to increased emphasis on employability (Jameson et al., 2012). In light of changing student lifestyles, there is increasing need to look to flexible ways to promote and deliver these types of support. 


\section{Changing delivery modes}

Efforts to widen participation (Department for Education and Skills, 2003) combined with social change have already altered student demographics and lifestyles. It remains to be seen whether offsetting payment until graduates are employed will actually achieve the stated aim of further widening participation (Independent Review of Higher Education and Student Finance in England, 2010) or whether the prospect of leaving university with much greater debt may deter low income students (Callender and Jackson, 2005) or those with external financial commitments.

Regardless, the trend of students spending increasing time on paid work is set to continue (Sodexo, 2012), part-time or distance learning may also become more common if more students choose to earn-while-they-learn to minimise the debt that they leave university with. Also, in a more competitive environment, universities are likely to look to increase their share of diverse markets such as international students. Students from increasingly diverse educational backgrounds with family or work commitments will require increasingly flexible learning opportunities and support.

Although the development of digital literacy is best enabled as situated practice (Beetham et al., 2010), there are vast differences in opportunities for students to engage with digital technologies in this way (Selwyn, 2010). For those students who do not have embedded opportunities to develop their digital literacy, we need to provide alternative forms of support.

According to the most recent Sodexo University Lifestyle Survey, 'half of all students [say] that they spend seven or more hours a week logged onto sites such as Facebook and Twitter' (Sodexo, 2012, p.11). This contrasts with the finding that 'the majority [of students] spent three hours or less [in the university library] in a typical week' (Sodexo, 2012, p.32).

To promote our Academic Skills Community, we have developed a Facebook page (Bournemouth University, 2012), which is promoted at induction sessions, on digital signage, in the VLE and via email notifications. Posts on the page raise awareness about both online and face-to-face support that is tailored to the seasonal demands for study skills guidance. At the time of writing, the page has been liked by 1,099 Facebook users. We should remember that the page's 'reach' goes beyond this as students who do not 
follow the page are exposed to the posts that their friends (who do follow the page) interact with.

Facebook Insights data reveals that the majority of likes are from UK-based Facebook users in the 18-24 age bracket. This data should not be taken as evidence that students outside of this age bracket are being excluded. The Facebook page is one of the many methods we use to communicate with students about support for study skills.

Encouragingly, the page has also received likes from Facebook users in other countries (such as the USA, Thailand and Lithuania) reflecting BU's international profile.

However, interaction with the Facebook page goes beyond 'likes'. We have received queries from current and prospective students through the Facebook page on varied topics such as where to find marking guidelines and the university's IELTS criteria. If we were not able to respond to a query ourselves, we gave the enquirer the relevant contact details. Our posts have been shared by other Facebook users, for example, a post promoting a workshop on finding information was shared by the Students' Union on their Facebook page with a tagline encouraging students to sign up. Finally, evaluation surveys of taught academic skills sessions suggested that some students had found out about the workshops via the Facebook page.

This use of social media sites is enabled by 'the pervasive nature of technology in learners' lives' (Beetham et al., 2009, p.61). Familiar technologies such as smart phones, tablets, laptops and social media offer us the opportunity to construct learning on social technology skills that students may already have (Trinder et al., 2008, p.51). Although 'even learners with their own laptop, smartphone and other devices may have no idea how best to use them to support their learning' (Beetham et al., 2009, p.15). For example, a discussion between two students on the Facebook page where one helped the other to access a referencing guide illustrates the potential of learners to support each other in developing digital literacy. By enabling peer-to-peer interaction, we can transcend our staff resources and opening times to capitalise on community support. Can we extend this concept of students supporting each other to one where they are actively involved in developing learning materials? 


\section{Student-focused materials}

One of the big questions we face is how paying more directly than ever for their education will change student expectations and engagement (Jones, 2010). It is possible that paying up to $£ 9,000$ per year will lead students to engage more to get the most from their university experience. However, it may be that they will expect to receive a qualification in return for their fees rather than for the effort that they put into their studies. The recent student lifestyle survey found $51 \%$ of respondents answering that they would demand more from their lecturers if they were paying $£ 9,000$ per annum, whereas just $25 \%$ said that they would spend more time studying (Sodexo, 2012, p.69).

There is increasing reference to students as 'customers' (Molesworth, 2009) but this kind of relationship exposes universities to increased scrutiny under consumer law (Philips, 2004). Recent legal cases (Hirsch, 2010) may lead institutions to consider whether seeing students as partners rather than customers may help to avoid the financial and reputational risk of customer-service style relationships.

Alongside changes to student expectations we are also seeing changes to the ways that students are expected to engage with learning. The use of technology in delivering education is widespread (Selwyn, 2010) and is often heralded as a potential solution to the challenges that universities face (Bradwell, 2009). However, a central irony is that it can also lead to resentment from students who do not necessarily see digital literacy as an enabling factor in their lives. Experience from BU library's online and face-to-face enquiry services, which support students accessing electronic books and journals, tells us that students do not always expect to develop digital literacy as part of their academic practice. Talking to library staff and reviewing enquiry transcripts reveals evidence of anger and resentment from students who do not always understand the need to develop the IT skills in order to access information in the modern world.

To address this conundrum, our strategy at BU is to involve students in the co-creation of learning materials and support: going beyond the passive consumption of content to take a more active role in creating and sharing knowledge with their peers. This is a paradigm shift from the traditional educational practice of '[w]e know, we teach you' to a situation where '[l]earners' digital skills [are] being recognised, rewarded and used as a resource for the learning community' (Beetham et al., 2009, p.67). By relating to students as partners 
(rather than customers) and involving them in every level of decision making we can ensure that they are aware of the limitations that we work within and they are true stakeholders, fully involved in deciding how their fees contribute towards their learning.

In a recent example, BU Media School students were commissioned to produce a short video highlighting key aspects of Library and Learning Support (Bournemouth University, 2011). Aside from the production quality being far better than anything we (as staff) could produce, the video very succinctly illustrates accessing our e-resources and support in the way the students who produced the video access them, rather than the way we (as information professionals) might try and show students.

BU were an early innovator of peer assisted learning (Parton and Fleming, 2007) and our programme (PAL) is now used universally across the institution. We also make good use of student assistants, employed by the library, to help other students to access systems and information. With all of these examples, we find a major benefit is that those students employed to develop the learning of others are also developed. We will increasingly look to involve students in learning development, for example, next year we plan to enable students to post on our Facebook page.

\section{Conclusion}

Increasing drivers for efficiency in higher education are likely to yield a period of organisational change, however, for supporting digital literacy we should embrace change as an opportunity to ensure that our organisational structures do not fragment support between different departments. Departments that have close working relations with academic colleagues (such as the library) can enable support that is embedded within curricula but can also provide a point of access linked to resource use for independent learners where this is not possible.

Increasingly diverse students and lifestyles are likely to lead to increasing demand for flexible, $24 \times 7$ support for skills development. Whilst technology can offer us efficient ways to deliver support (for example online chat services) we should not ignore the potential of social media as an efficient enabler for peer support. 
This concept of involving students as partners in their learning can be extended to engage students in co-creating learning objects. This represents a game-changing shift of the power dynamic of higher education, with university staff moving from being experts, to being enablers of learning. This paradigm shift has interesting potential for the development of learning in higher education but may also offer solutions to changing student expectations through involving students as partners in owning their educational opportunities.

\section{References}

Beetham, H., Littlejohn, A. and McGill, L. (2010) 'Beyond competence: digital literacies as knowledge practices, and implications for learner development', ESRC Seminar Series Literacies for the Digital University, Seminar Two. Glasgow Caledonian University, Glasgow 1 March. Glasgow: Glasgow Caledonian University: Literacy in the Digital University.

Beetham, H., McGill, L. and Littlejohn, A. (2009) Thriving in the 21st century: learning literacies for the digital age (LLiDA project). Glasgow, UK: Caledonian Academy, Glasgow Caledonian University.

Biddiscombe, R. (1999) 'Managing the new learning agenda in a converged service environment', in The future of libraries in human communication: proceedings of the 20 ${ }^{\text {th }}$ IATUL conference. Chania, Greece 17-21 May. Gothenburg : IATUL, paper 3.

Biddiscombe, R. (2002) 'Learning support professionals: the changing role of subject specialists in UK academic libraries', Program: Electronic Library and Information Systems, 36(4), pp. 228-235.

Bournemouth University (2011) New! BU Library in 60 seconds. Available at: http://www.youtube.com/watch?v=xm06rDjVeDI (Accessed: 21 June 2012).

Bournemouth University (2012) Bournemouth University Academic Skills. Available at: http://www.facebook.com/BUAcademicSkills (Accessed: 26 June 2012). 
Bradwell, P. (2009) The edgeless university: why higher education must embrace technology. London: Demos.

Callender, C. and Jackson, J. (2005) 'Does the fear of debt deter students from higher education?', Journal of Social Policy, 34(4), pp. 509-540.

Department for Business Innovation and Skills (2011) Higher education: students at the heart of the system. London: Department for Business Information and Skills.

Department for Education and Skills (2003) Widening participation in higher education. London: Department for Education and Skills.

Goodfellow, R. (2011) 'Literacy, literacies and the digital in higher education', Teaching in Higher Education, 16(1), pp. 131-144.

Hanson, T. (2005) Managing academic support services in universities: the convergence experience. London: Facet, 2005.

Hirsch, A. (2010) It's not just law students who are learning how to sue. Afua Hirsch's Law Blog. London: The Guardian.

Independent Review of Higher Education and Student Finance in England (2010) Securing a sustainable future for higher education. London: Independent Review of Higher Education and Student Finance in England.

Jameson, J., Strudwick, K., Bond-Taylor, S. and Jones, M. (2012) 'Academic principles versus employability pressures: a modern power struggle or a creative opportunity?', Teaching in Higher Education, 17(1), pp. 25-37.

Jones, G. (2010) 'Managing student expectations', Perspectives: Policy and Practice in Higher Education, 14(2), pp. 44-48.

Molesworth, M.E.R. (2009) 'Having, being and higher education: the marketisation of the university and the transformation of the student into consumer', Teaching in Higher Education, 14(3), pp. 277-287. 
Ooms, A., Burke, L., Linsey, T. and Heaton-Shrestha, C. (2008) 'Introducing e-developers to support a university's blended learning developments', ALT-J: Research in Learning Technology, 16(2), pp. 111-122.

Parton, S. and Fleming, H. (2007) 'Academic libraries and learning support in collaboration', New Review of Academic Librarianship, 13(1/2), pp. 79-89.

Philips, A.F. (2004) 'Some legal aspects of the student as a 'consumer': specialisms for generalists', Perspectives London Policy and Practice in Higher Education, 8(2), pp. 41-44.

Selwyn, N. (2010) 'Degrees of digital dvision: reconsidering digital inequalities and contemporary higher education' ('Grados de la división digital: Reconsideración de las desigualdades digitales y educación superior contemporánea'), Revista de Universidad y Sociedad del Conocimiento, 7(1), p. 33.

Sodexo (2012) Sodexo uni lifestyle survey. Southampton: Sodexo in association with Times Higher Education.

Student and Academic Services (2010) BU guide to citation in the Harvard style. Bournemouth: Bournemouth University.

Trinder, K., Guiller, J., Margaryan, A., Littlejohn, A. and Nicol, D. (2008) Learning from digital natives: bridging formal and informal learning. Glasgow: Glasgow Caledonian University, The Higher Education Academy.

\section{Author details}

Neil Ford is Academic Liaison Development Manager at Bournemouth University.

Melissa Bowden is Academic Support Librarian (Law) at Bournemouth University. 